\title{
Simulation and Fabrication of Gated Silicon Drift X-Ray Detector Operated by Peltier Cooling
}

\author{
Hideharu Matsuura $^{1, *}$, Derek Hullinger ${ }^{2}$ and Keith W. Decker ${ }^{2}$ \\ ${ }^{1}$ Osaka Electro-Communication University, 18-8 Hatsu-cho, Neyagawa, Osaka 572-8530, Japan \\ ${ }^{2}$ MOXTEK, Inc., 452 West 1260 North, Orem, UT 84057, USA
}

\begin{abstract}
A proposed simply structured gated silicon (Si) drift X-ray detector operated using Peltier cooling and only a single high-voltage source is investigated. Because the device structure is much simpler than that of commercial Si drift detectors (SDDs), which require at least two high-voltage sources, the cost of the X-ray detection system can be reduced. The absorption of cadmium X-ray fluorescence photons (energy: $23.1 \mathrm{keV}$ ) in $0.3-\mathrm{mm}$-thick Si is only $19 \%$ in commercial SDDs. Toward realizing detectors with thicker Si substrates, we simulate the electric potential distribution in the proposed detector with a Si substrate having thickness of $0.625 \mathrm{~mm}$ and resistivity of $10 \mathrm{k} \Omega \cdot \mathrm{cm}$, and we perform fundamental experiments on a fabricated prototype. The simulation result is in good agreement with the experimental result that the effective active area of the detector is approximately $18 \mathrm{~mm}^{2}$ by using incident X-rays passed through a 0.1 -mm-diameter pinhole. An energy resolution of $145 \mathrm{eV}$ at $5.9 \mathrm{keV}$ is experimentally obtained from an ${ }^{55} \mathrm{Fe}$ source at $-38{ }^{\circ} \mathrm{C}$.
\end{abstract}

Keywords: Simple structure, Inexpensive detector, Gated silicon drift detector, Thick silicon, High-resistivity silicon, High sensitivity to high-energy X-rays.

\section{INTRODUCTION}

Silicon (Si) p-type /intrinsic /n-type (pin) detectors and $\mathrm{Si}$ drift detectors (SDDs) [1-7] are used to measure the energies and counts of incoming X-ray fluorescence photons with low energies. A pin diode can be used to collect charge carriers, the number of which is proportional to the X-ray photon energy. In general, the capacitance of the detector increases as the active area (i.e., the entrance window) becomes larger, thus degrading performance. To lower the capacitance, the SDD shown in Fig. (1) has been proposed [1]. The anode (n layer) of this SDD is smaller than that of a pin diode, and is located on one surface of the $n^{-}$-type $\mathrm{Si}$ substrate $\left(\mathrm{n}^{-}\right.$or $\mathrm{i}$ layer). A large entrance window layer (cathode or p layer) is located on the opposite surface. The anode is surrounded by multiple $\mathrm{p}$-type rings ( $\mathrm{p}$ rings) to which a bias is applied such that an electric field is generated, causing electrons to smoothly flow toward the anode. To form a suitable electric field in commercial SDDs, the p rings are electrically coupled by implanted resistors or metal-oxide-semiconductor field-effect transistors (MOSFETs) as shown in Fig. (1). SDDs with MOSFETs or implanted resistors are costly to manufacture, so we have designed several simple SDDs that are free of MOSFETs or implanted resistors [8-13].

In the case of cadmium (Cd), for example, to detect trace amounts of this hazardous element in foods and soil, the absorption of Cd X-ray fluorescence photons (energy: 23.1

*Address correspondence to this author at the Osaka ElectroCommunication University, 18-8 Hatsu-cho, Neyagawa, Osaka 572-8530, Japan; Tel.: +81-72-820-9031; Fax: +81-72-820-9031;

E-mail: matsuura@isc.osakac.ac.jp
$\mathrm{keV}$ ) should be $>50 \%$. Because the i layer in commercial SDDs is between 0.3 and $0.5 \mathrm{~mm}$ thick, however, the absorption of Cd X-ray fluorescence is low, between $19 \%$ and $30 \%$. In a $1-\mathrm{mm}$-thick Si substrate, on the other hand, the absorption reaches $51 \%$. Accordingly, thicker Si X-ray detectors have been investigated [14-16]. In addition to low cost and high sensitivity to high-energy X-ray photons, detectors should be portable. This means that the cooling mechanism should also be compact and portable; these conditions are satisfied by a Peltier cooler. Against this background, we have been working to develop thick, simply structured Si Xray detectors operated by Peltier cooling $[12,13]$.

To incorporate thicker Si substrates into X-ray detectors, here we propose a simply structured detector that has a 10$\mathrm{k} \Omega \cdot \mathrm{cm}$ Si substrate with thickness of $0.625 \mathrm{~mm}$, the greatest thickness possible through our fabrication process.

\section{DEVICE SIMULATION OF SIMPLY STRUC- TURED X-RAY DETECTOR}

To operate an X-ray detector with a thick Si substrate at a reasonable reverse bias, the $\mathrm{n}^{-} \mathrm{Si}$ substrate should have resistivity greater than $5 \mathrm{k} \Omega \cdot \mathrm{cm}$, which corresponds to donor density less than $10^{12} \mathrm{~cm}^{-3}$, while the $\mathrm{n}^{-} \mathrm{Si}$ substrate in commercial SDDs has resistivity of approximately $2 \mathrm{k} \Omega \cdot \mathrm{cm}$. In SDDs with high-resistivity Si substrates, however, large hole current flows between the cathode and some $p$ rings, owing to the large difference in voltage between them $[12,13]$.

Fig. (2) shows a cross-sectional schematic of a cylindrical simply structured SDD with only a single $p$ ring; this detector is referred to as $\operatorname{SSDD}[8,9,12]$; this detector does 


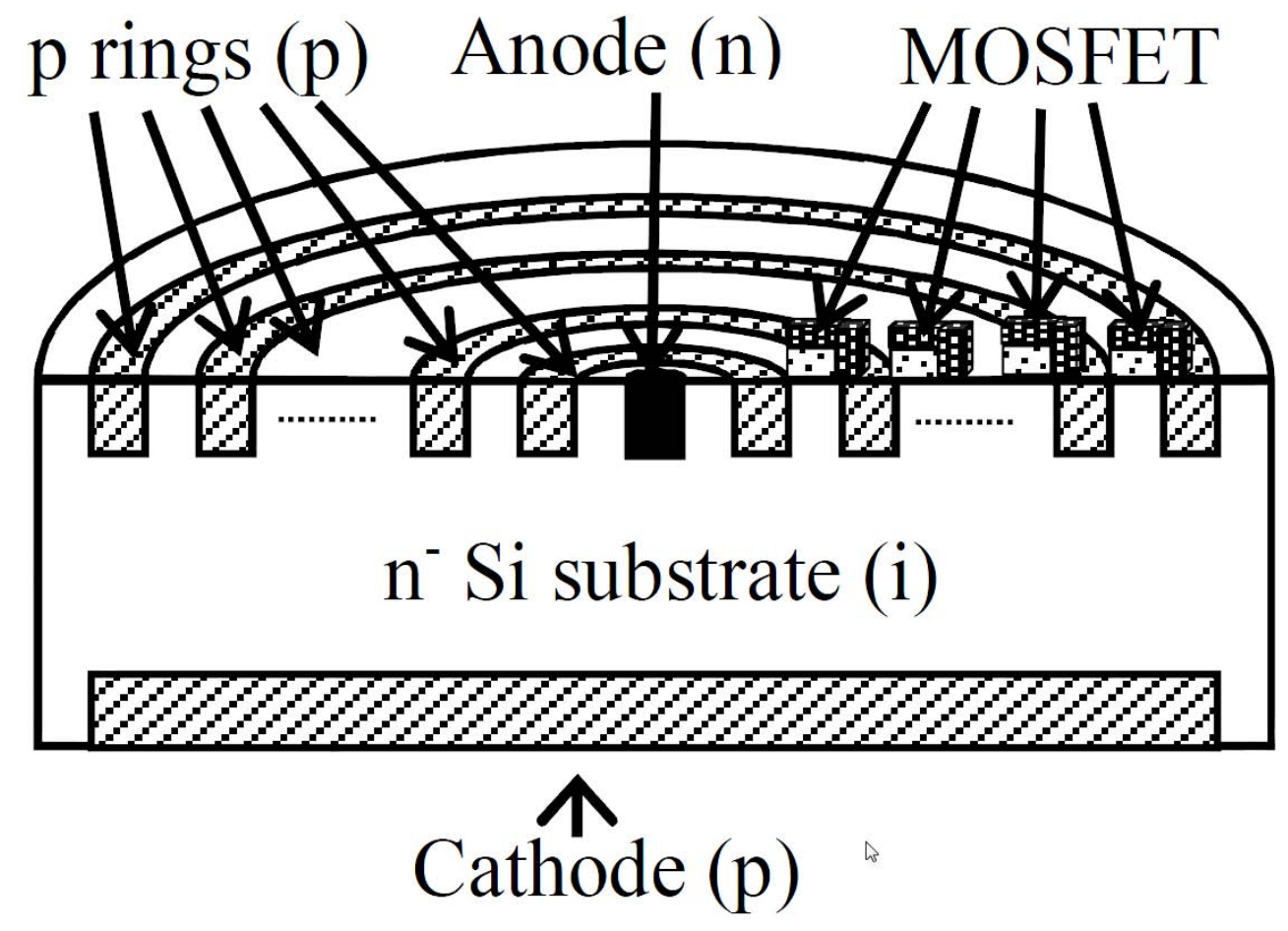

Fig. (1). Schematic half-structure and cross section of commercial SDD with MOSFETs between p rings.

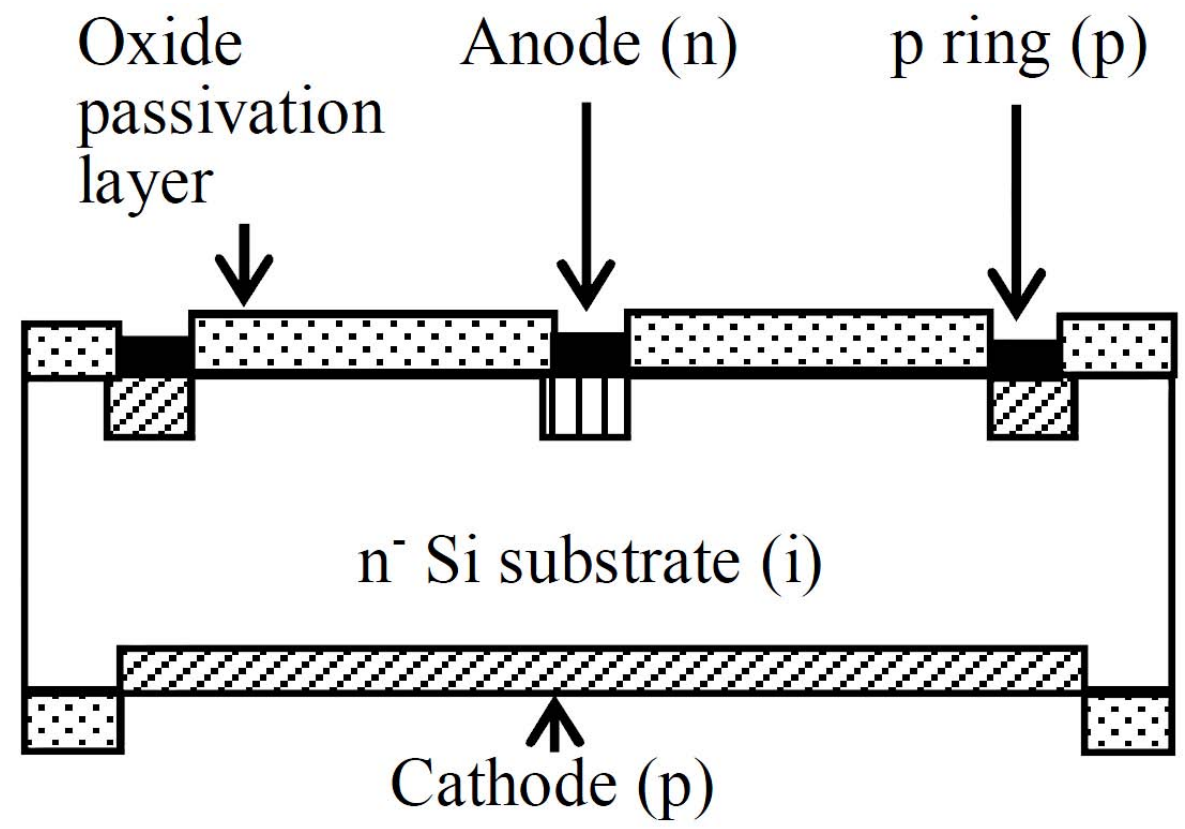

Fig. (2). Cross-sectional schematic of cylindrical simply structured SDD with a single p ring (SSDD). The same negative bias can be applied to the cathode and $p$ ring.

not have MOSFETs or implanted resistors. As shown in Fig. (2), the same high negative bias can be applied across the cathode and the $\mathrm{p}$ ring. The anode is connected to the junction FET in a pre-amplifier. An oxide layer $\left(\mathrm{SiO}_{2}\right)$ is formed as a passivation layer, as in almost all Si devices.

The following device simulations were carried out by using technology-computer-aided design software (ATLAS, Silvaco). In the simulation, the $\mathrm{n}^{-} \mathrm{Si}$ substrate had thickness of $0.625 \mathrm{~mm}$ and resistivity of $10 \mathrm{k} \Omega \cdot \mathrm{cm}$. The radius of the anode was $0.055 \mathrm{~mm}$. The inner and outer radii of the $\mathrm{p}$ ring were 2.455 and $3.050 \mathrm{~mm}$, respectively. The acceptor densities of the cathode and the $\mathrm{p}$ ring were $1 \times 10^{18} \mathrm{~cm}^{-3}$, and the donor density of the anode was $1 \times 10^{19} \mathrm{~cm}^{-3}$. The thicknesses of the cathode, $\mathrm{p}$ ring, and anode were $1 \mu \mathrm{m}$. The thickness of the $\mathrm{SiO}_{2}$ passivation layer was $0.75 \mu \mathrm{m}$, and the positive fixed oxide charge sheet density $\left(Q_{\mathrm{F}}\right)$ in $\mathrm{SiO}_{2}$ near the $\mathrm{SiO}_{2} / \mathrm{Si}$ interface was varied. A reverse bias of $-90 \mathrm{~V}$ was applied to the cathode and $\mathrm{p}$ ring. 


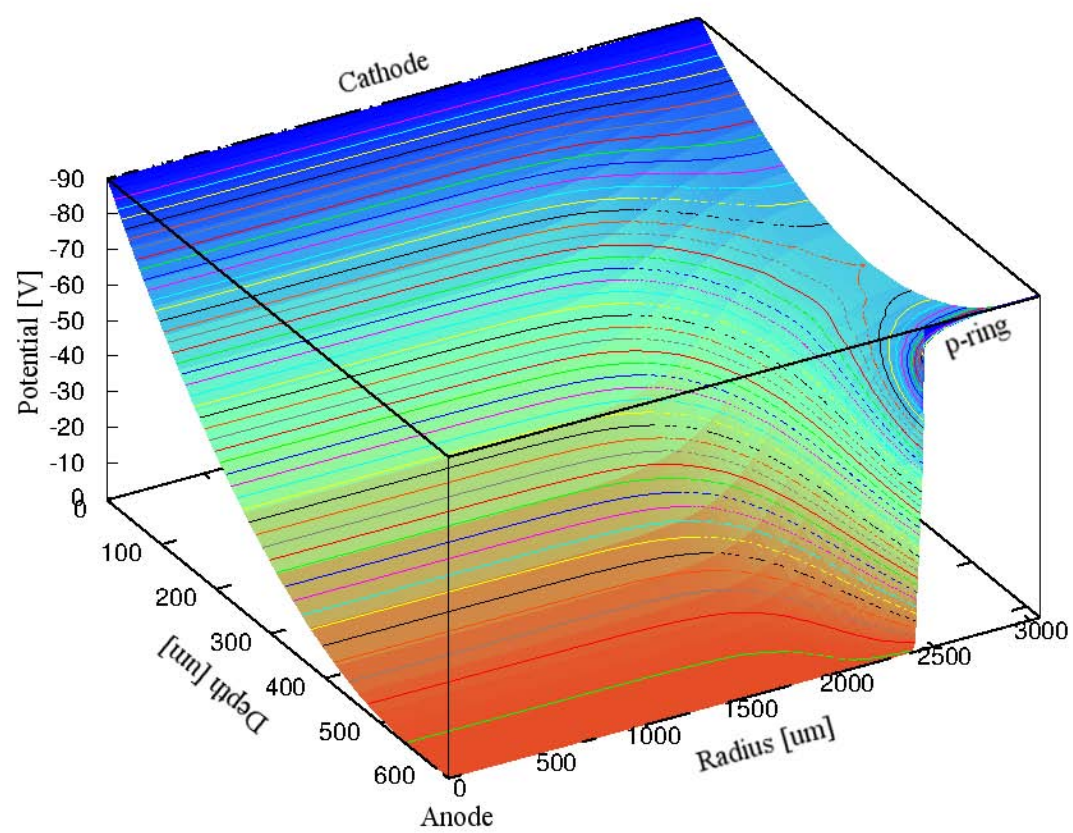

Fig. (3). Simulated electric potential distribution in $0.625-\mathrm{mm}$-thick $10-\mathrm{k} \Omega \cdot \mathrm{cm}$ Si substrate of SSDD. The cathode and p ring were biased at 90 V. $Q_{\mathrm{F}}$ in $\mathrm{SiO}_{2}$ near the $\mathrm{SiO}_{2} / \mathrm{Si}$ interface was assumed to be $3 \times 10^{10} \mathrm{~cm}^{-2}$.

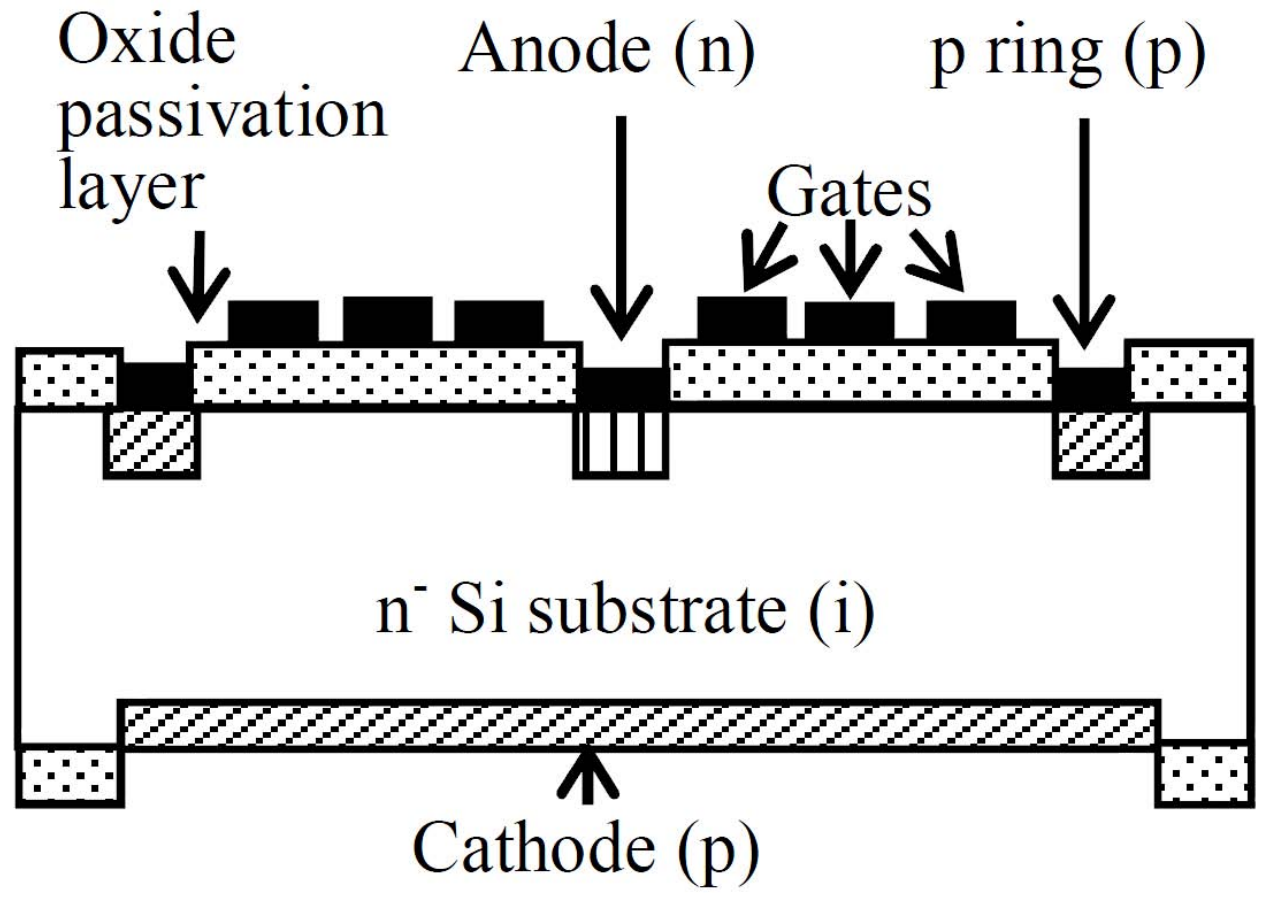

Fig. (4). Cross-sectional schematic of cylindrical GSDD with one p ring and several gates. The same negative voltage was applied to the cathode, $\mathrm{p}$ ring, and all gates.

Fig. (3) shows the electric potential distribution in the $\mathrm{Si}$ substrate of the SSDD with $Q_{\mathrm{F}}=3 \times 10^{10} \mathrm{~cm}^{-2}$, which has been reported for current processing methods [17]. Because the voltage drop near the $\mathrm{p}$ ring was large, the potential near the $\mathrm{SiO}_{2} / \mathrm{Si}$ interface was almost zero. Therefore, the electrons produced by an X-ray photon flow toward the $\mathrm{SiO}_{2} / \mathrm{Si}$ interface, not toward the anode, and then recombine with holes at the interface.
Fig. (4) shows the cross-sectional schematic of a cylindrical SDD with several ring-shaped gates and one $p$ ring; this detector is referred to as a gated SDD (GSDD) [10, 11]. The gates (composed of metal) are formed on the oxide passivation layer during metallization of the anode and the $p$ ring, so no additional processes are required in order to form the gates. Compared with a commercial SDD, GSDD is much simpler to fabricate. The same high reverse bias is 


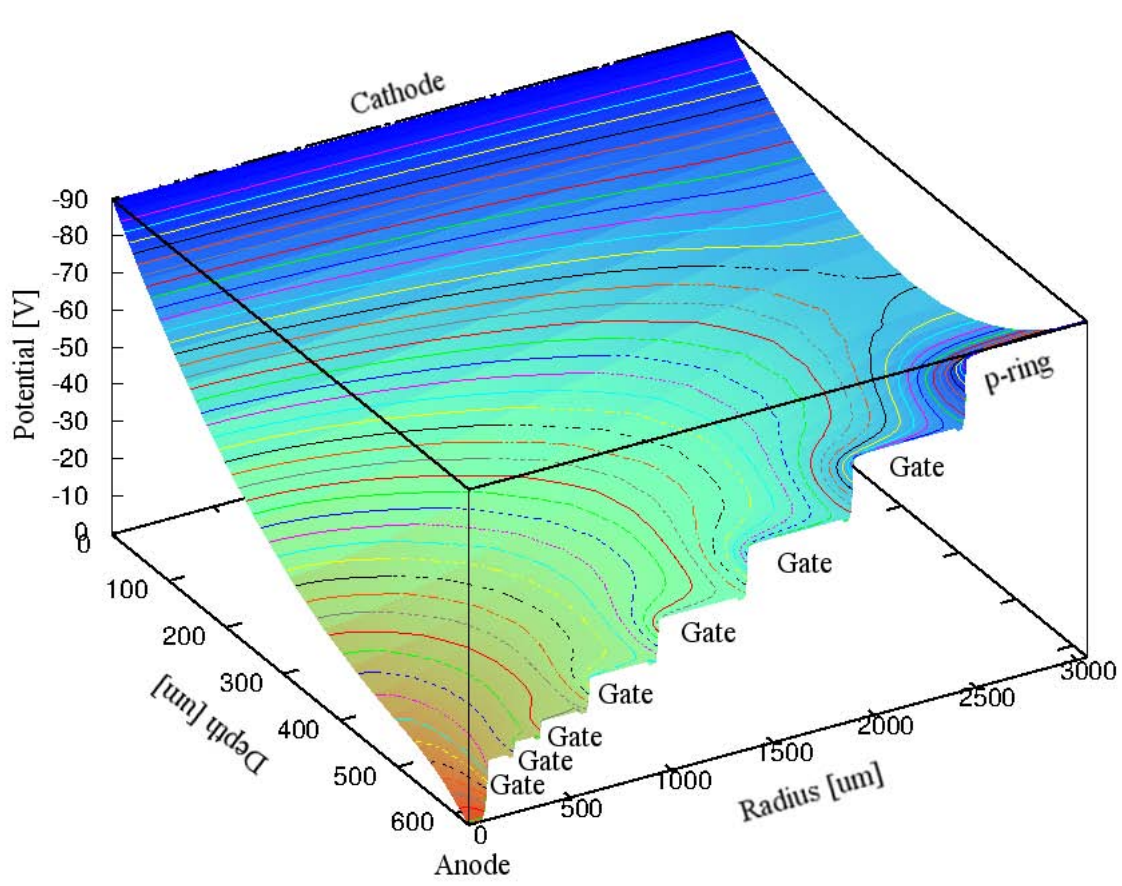

Fig. (5). Simulated electric potential distribution in $0.625-\mathrm{mm}$-thick $10-\mathrm{k} \Omega \cdot \mathrm{cm}$ Si substrate of GSDD. The cathode, p ring, and seven gates were biased at -90 V. $Q_{\mathrm{F}}$ in $\mathrm{SiO}_{2}$ near the $\mathrm{SiO}_{2} / \mathrm{Si}$ interface was assumed to be $3 \times 10^{10} \mathrm{~cm}^{-2}$.

applied to the cathode, p ring, and all gates, which means that the GSDD requires only a single high-voltage source. In this way, the cost of the X-ray detection system can be greatly reduced.

In the simulation, seven gates were used. Their widths were $0.10,0.10,0.19,0.29,0.39,0.47$, and $0.51 \mathrm{~mm}$, from the innermost to outermost gate. The gap between the anode and the innermost gate was $0.04 \mathrm{~mm}$, and the gap between the innermost and second gates, as well as the gap between the second and third gates, was $0.03 \mathrm{~mm}$. The other gaps between the gates, and the gap between the outermost gate and the $\mathrm{p}$ ring, were $0.05 \mathrm{~mm}$.

Fig. (5) shows the electric potential distribution in the $\mathrm{Si}$ substrate of GSDD with $Q_{\mathrm{F}}=3 \times 10^{10} \mathrm{~cm}^{-2}$. In this electric potential distribution, the electric field along the electric potential valley was strong enough that all electrons produced by X-ray photons smoothly flowed toward the anode. The simulation shows that the electrons produced in the area within the $\mathrm{p}$ ring can be collected at the anode, corresponding to an effective active area of approximately $18 \mathrm{~mm}^{2}$.

The drift time is longer for electrons produced farther from the anode. When electrons flow far from the anode, however, they induce positive charges at the $\mathrm{p}$ ring, gates, and cathode, but not at the anode, indicating that the induced current does not appear at the anode. When the electrons drift between the anode and the innermost gate, the induced current signal is detected at the anode. Therefore, the signal rise time remains short even in the GSDD with a large entrance window.

The value of $Q_{\mathrm{F}}$ is strongly dependent on how the oxide passivation layer is formed. The widths of the gates and the gaps should be designed to ensure effective detector operation even when $Q_{\mathrm{F}}$ is changed by the fabrication processes; accordingly, the electric potential distributions for several $Q_{\text {F }}$ values were simulated.

Fig. (6) shows the electric potential distribution in the $\mathrm{Si}$ substrate of the GSDD with $Q_{\mathrm{F}}$ of 0 , which is an ideal but impractical condition. In this case, the electric field between the anode and the innermost $\mathrm{p}$ ring is strong, and the electric field in the other areas is weak, indicating that electrons produced by an X-ray photon far from the anode take a long time to reach it.

We next consider realistic $Q_{\mathrm{F}}$ values of $1 \times 10^{10}$ (good) and $1 \times 10^{12} \mathrm{~cm}^{-2}$ (poor), for which Figs. (7) and (8) respectively show the electric potential distributions in the GSDD Si substrate. The results indicate that the GSDD functions well, even if there is variation in $Q_{\mathrm{F}}$.

\section{FABRICATION}

GSDDs with the design discussed in Section 2 were fabricated using $0.625-\mathrm{mm}^{-}$-thick $\mathrm{n}^{-} \mathrm{Si}$ substrates with resistivity of $10 \mathrm{k} \Omega \cdot \mathrm{cm}$. To fabricate the $\mathrm{p}$ ring, boron (B) ions were implanted into one side of the substrate, which was then annealed. To produce an anode at the center of the GSDD, phosphorus ions were implanted into the same side, and then the sample was annealed. To form the $p$ layer of the entrance window on the opposite side, B ions were implanted and then the sample was annealed. After these processes, a $\mathrm{SiO}_{2}$ passivation layer of approximately $0.75 \mu \mathrm{m}$ in thickness was formed on the surface. When the anode and the $p$ ring were metallized, the seven ring-shaped gates were formed. The fabrication details have been reported elsewhere $[12,13]$. 


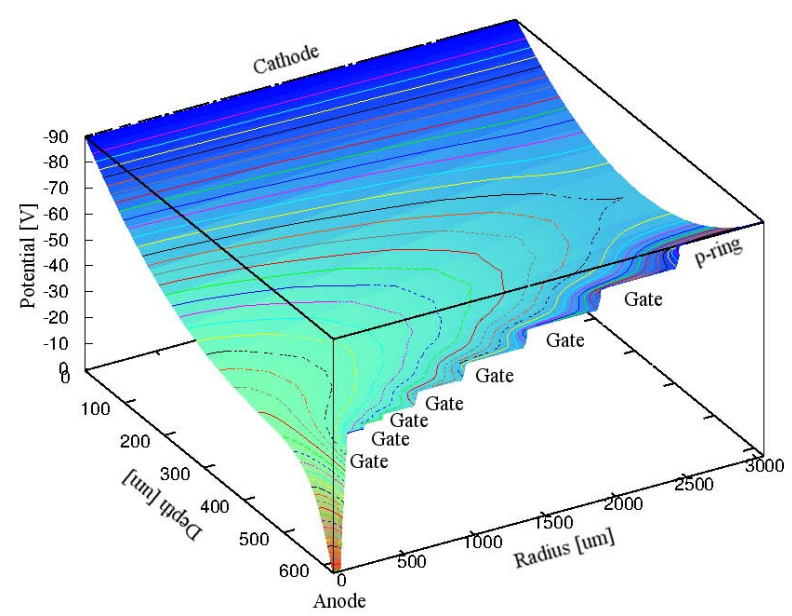

Fig. (6). Simulated electric potential distribution in $0.625-\mathrm{mm}$-thick $10-\mathrm{k} \Omega \cdot \mathrm{cm}$ Si substrate of GSDD. The cathode, p ring, and seven gates were biased at -90 V. $Q_{\mathrm{F}}$ in $\mathrm{SiO}_{2}$ near the $\mathrm{SiO}_{2} / \mathrm{Si}$ interface was assumed to be zero (ideal).

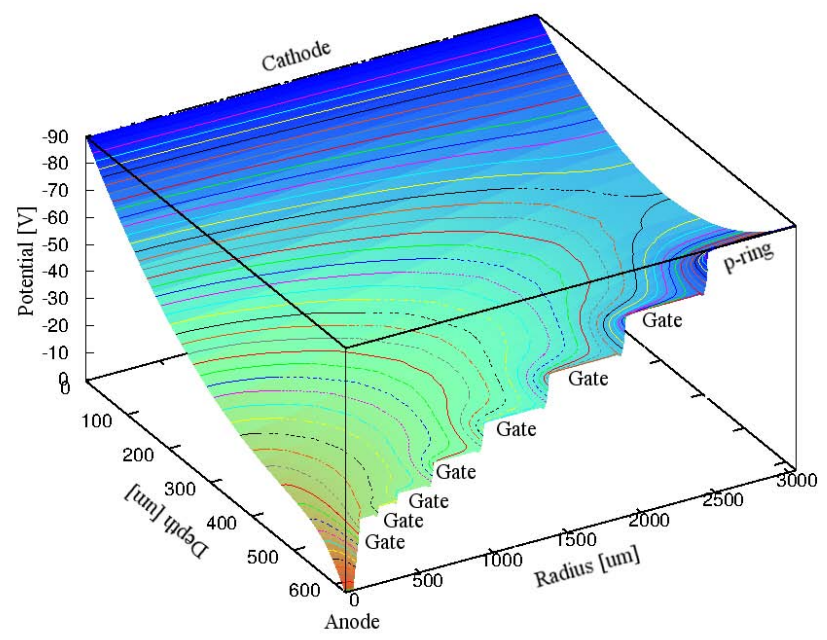

Fig. (7). Simulated electric potential distribution in $0.625-\mathrm{mm}$-thick $10-\mathrm{k} \Omega \cdot \mathrm{cm}$ Si substrate of GSDD. The cathode, p ring, and seven gates were biased at -90 V. $Q_{\mathrm{F}}$ in $\mathrm{SiO}_{2}$ near the $\mathrm{SiO}_{2} / \mathrm{Si}$ interface was assumed to be $1 \times 10^{10} \mathrm{~cm}^{-2}$ (good).

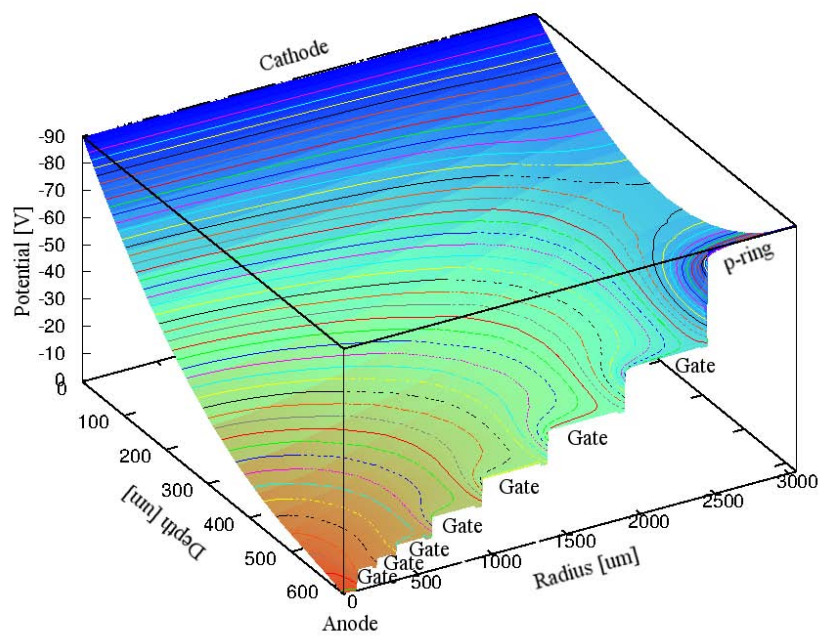

Fig. (8). Simulated electric potential distribution in $0.625-\mathrm{mm}$-thick $10-\mathrm{k} \Omega \cdot \mathrm{cm}$ Si substrate of GSDD. The cathode, $\mathrm{p}$ ring, and seven gates were biased at -90 V. $Q_{\mathrm{F}}$ in $\mathrm{SiO}_{2}$ near the $\mathrm{SiO}_{2} / \mathrm{Si}$ interface was assumed to be $1 \times 10^{12} \mathrm{~cm}^{-2}$ (poor). 


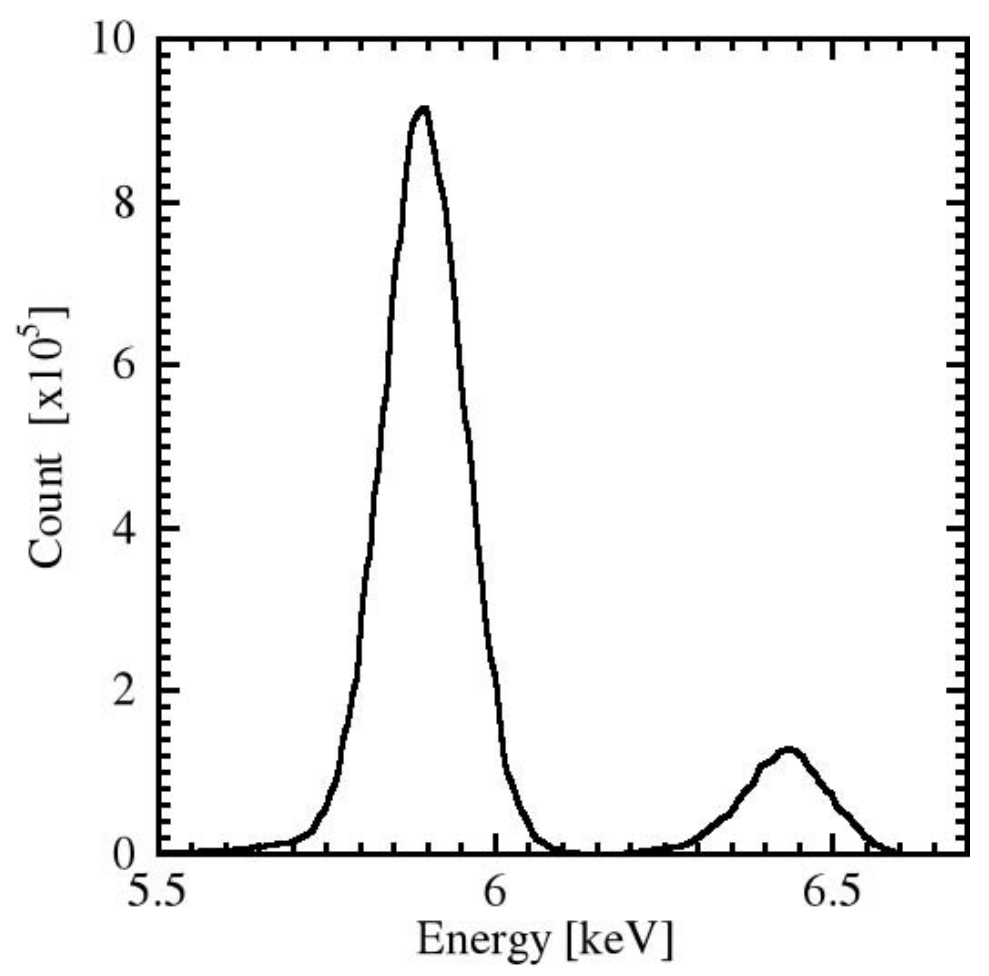

Fig. (9). ${ }^{55} \mathrm{Fe}$ spectrum for $0.625-\mathrm{mm}$-thick GSDD with $10-\mathrm{k} \Omega \cdot \mathrm{cm}$ Si substrate at $-38{ }^{\circ} \mathrm{C}$ and shaping time of $2 \mu$ s.

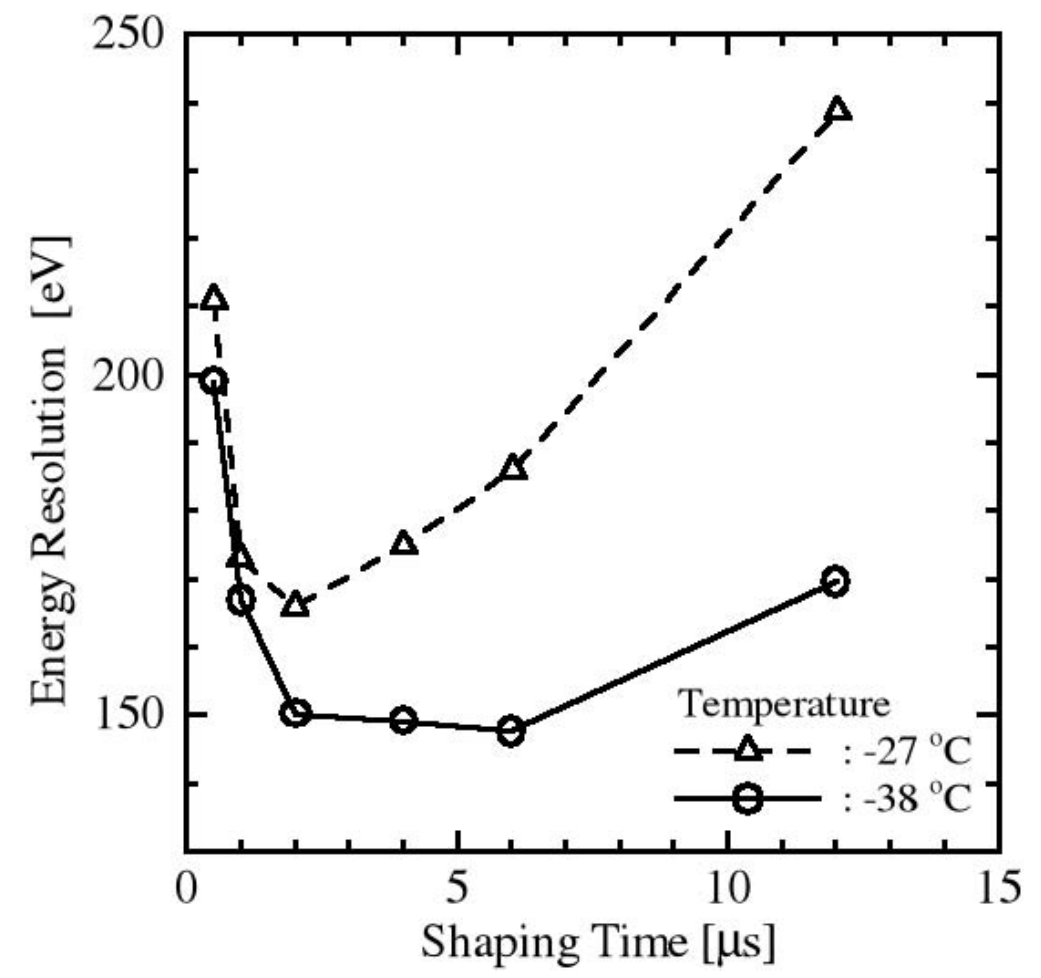

Fig. (10). Dependence on shaping time of energy resolution for $0.625-\mathrm{mm}$-thick GSDD with $10-\mathrm{k} \Omega \cdot \mathrm{cm}$ Si substrate at -27 and $-38{ }^{\circ} \mathrm{C}$.

\section{EXPERIMENTAL RESULTS AND DISCUSSION}

As in the simulation, $-90 \mathrm{~V}$ was applied to the cathode, $\mathrm{p}$ ring, and all gates to form a suitable electric field in the GSDD.

Fig. (9) shows the ${ }^{55} \mathrm{Fe}$ spectrum of the GSDD at $-38{ }^{\circ} \mathrm{C}$ and a shaping time of $2 \mu \mathrm{s}$. An energy resolution of $151 \mathrm{eV}$ was obtained. Fig. (10) shows the dependence on shaping time of the energy resolutions measured from the ${ }^{55} \mathrm{Fe}$ source at $-27{ }^{\circ} \mathrm{C}(\triangle)$ and $-38{ }^{\circ} \mathrm{C}(\mathrm{\circ})$. At $-38{ }^{\circ} \mathrm{C}$ and a shaping time of $6 \mu \mathrm{s}$, an energy resolution of $145 \mathrm{eV}$ was obtained at 5.9 $\mathrm{keV}$.

Fig. (11) shows the ${ }^{55} \mathrm{Fe}$ spectrum of the GSDD on a semi-log scale at $-38{ }^{\circ} \mathrm{C}$ and a shaping time of $2 \mu \mathrm{s}$. The 


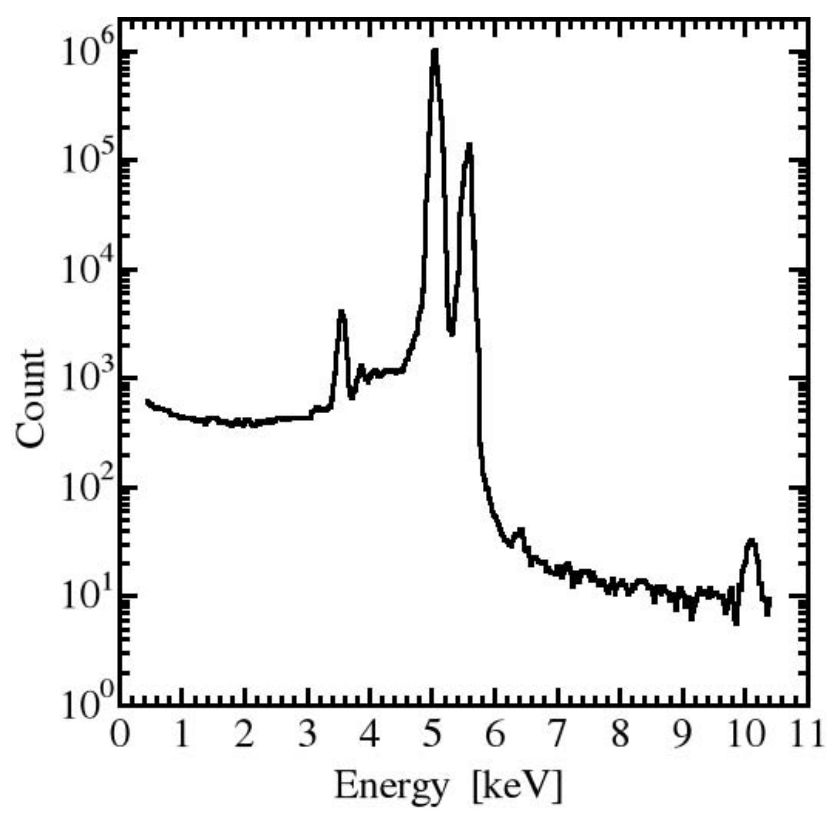

Fig. (11). ${ }^{55} \mathrm{Fe}$ spectrum on semi-log scale for $0.625-\mathrm{mm}$-thick GSDD with $10-\mathrm{k} \Omega \cdot \mathrm{cm}$ Si substrate at $-38{ }^{\circ} \mathrm{C}$ and shaping time of $2 \mu$ s.

peak-to-background ratio was 2208 and 726 at 2 and $5 \mathrm{keV}$, respectively, which is poor, likely because the entrance window layer had not been optimized to achieve a high peak-tobackground ratio.

The counts produced in the GSDD irradiated with X-ray photons through a $0.1-\mathrm{mm}$-diameter pinhole were mapped by moving the detector at $0.1-\mathrm{mm}$ increments [13]. An area of consistent counts clearly appeared, which corresponds to the active area of the X-ray detector. The active area was approximately $18 \mathrm{~mm}^{2}$, which is consistent with the simulation result (i.e., the circular area with an inner radius of the $\mathrm{p}$ ring).

\section{CONCLUSIONS}

A GSDD was proposed for realizing a portable and inexpensive Si X-ray detector that is sensitive to X-ray photons with energies up to $25 \mathrm{keV}$ and can be operated by Peltier cooling. Through device simulation, excellent electric potential distributions in GSDDs were obtained for realistic values of positive fixed oxide charge densities between $1 \times 10^{10}$ and $1 \times 10^{12} \mathrm{~cm}^{-2}$ in the oxide passivation layer near the $\mathrm{SiO}_{2} / \mathrm{Si}$ interface. Moreover, GSDD prototypes with $0.625-\mathrm{mm}$-thick $10-\mathrm{k} \Omega \cdot \mathrm{cm}$ Si substrates functioned well under Peltier cooling. The results suggest that GSDDs with thicker Si substrates are feasible.

\section{CONFLICT OF INTEREST}

The authors confirm that this article content has no conflicts of interest.

\section{ACKNOWLEDGEMENT}

The authors thank K. Taniguchi and T. Utaka of Techno X Co., Ltd., and S. Kitanoya, S. Nishikawa, and R. Okada in Matsuura laboratory, for helpful discussion.

\section{REFERENCES}

E. Gatti and P. Rehak, "Semiconductor drift chamber - an application of a novel charge transport scheme", Nucl. Instrum. Methods, vol. 225, pp. 608-614, September 1984.
[2] G. Bertuccio and A. Pullia, "Room temperature X-ray spectroscopy with a silicon diode detector and an ultra low noise preamplifier", IEEE Trans. Nucl. Sci., vol. 4, pp. 1704-1709, August 1994.

[3] P. Lechner, S. Eckbauer, R. Hartmann, S. Krisch, D. Hauff, R Richter, H. Soltau, L. Strüder, C. Fiorini, E. Gatti, A. Longoni, and M. Sampietro, "Silicon drift detectors for high resolution room temperature X-ray spectroscopy”, Nucl. Instrum. Methods Phys. Res. A, vol. 377, pp. 346-351, August 1996.

[4] C. Fiorini, J. Kemmer, P. Lechner, K. Kromer, M. Rohde, and T. Schülein, "A new detection system for X-ray microanalysis based on a silicon drift detector with Peltier cooling", Rev. Sci. Instrum., vol. 68, pp. 2461-2465, June 1997.

[5] L. Strüder, N. Meidinger, D. Stotter, J. Kemmer, P. Lechner, P. Leutenegger, H. Soltau, F. Eggert, M. Rohde, and T. Schülein, "High-resolution X-ray spectroscopy close to room temperature", Microsc. Microanal., vol. 4, pp. 622-631, July 1998.

[6] P. Lechner, A. Pahlke, and H. Soltau, "Novel high-resolution silicon drift detectors", X-Ray Spectrom., vol. 33, pp. 256-261, January 2004.

[7] J. Kemmer, F. Wiest, A. Pahlke, O. Boslau, P. Goldstrass, T. Eggert, M. Schindler, and I. Eisele, "Epitaxy - a new technology for fabrication of advanced silicon radiation detectors", Nucl. Instrum. Methods. Phys. Res. A, vol. 544, pp. 612-619, June 2005.

[8] H. Matsuura, K. Taniguchi, and T. Utaka, "Radiation detectiondevice", Japan Patent Application No. 2006-336727, October 14, 2006; Japan Patent Publication No. 2008-153256, July 3, 2008; U. S. Patent Application Serial No. 61/185,679, June 10, 2009.

[9] H. Matsuura, K. Taniguchi, and T. Utaka, "Radiation detection device", Japan Patent Application No. 2007-098037, April 4, 2007; Japan Patent Publication No. 2008-258348, October 23, 2008; U. S. Patent Application Serial No. 61/185,754, June 10, 2009.

[10] H. Matsuura, "Radiation detection device", Japan Patent Application No. 2009-157627, July 2, 2009; Japan Patent Publication No. 2011-014718, January 20, 2011; U. S. Patent Application Serial No. 12/575,939, October 8, 2009.

[11] D. Hullinger, H. Matsuura, K. Taniguchi, and T. Utaka, "Variable ring width SDD", U.S. 8,314,468, November 20, 2012.

[12] H. Matsuura, M. Takahashi, K. Kohara, K. Yamamoto, T. Maeda, and Y. Kagawa, "Simplification of structures and improvement of sensitivity of high-energy X-rays for Si X-ray detectors (silicon drift detector)", IEICE Trans. Electronics, vol. J93-C, no. 9, pp. 303-310, September 2010 (in Japanese).

[13] H. Matsuura, D. Hullinger, R. Okada, S. Kitanoya, S. Nishikawa, and K. Decker, "Possibilities for thick, simple-structure silicon Xray detectors operated by peltier cooling", Key Eng. Mater., vol. 495, pp. 294-297, November 2012.

[14] C. R. Tull, J. S. Iwanczyk, B. E. Patt, S. Barkan, and L. Feng, "High efficiency silicon X-ray detectors", IEEE Trans. Nucl. Sci., vol. 51, pp. 1803-1807, August 2004. 
[15] S. I. Parker, C. J. Kenney, and J. Segal, "3D - a proposed new architecture for solid-state radiation detectors", Nucl. Instrum. Methods. A, vol. 395, pp. 328-343, August 1997.
[16] M. Christophersen and B. F. Phlips, "Thick silicon drift detector", in IEEE Nucl. Sci. Symp. Conf. Record., 2008, pp. 2727-2730 (N34-5).

[17] B. L. Anderson and R. L. Anderson, Fundamentals of Semiconductor Devices. McGraw-Hill: Boston, 2005.

Received: October 09, 2012

(C) Matsuura et al.; Licensee Bentham Open.

This is an open access article licensed under the terms of the Creative Commons Attribution Non-Commercial License (http://creativecommons.org/licenses/by-nc/3.0/) which permits unrestricted, non-commercial use, distribution and reproduction in any medium, provided the work is properly cited. 